\title{
SISTEM KENDALI PENERANGAN RUANGAN UNTUK MENGURANGI KONSUMSI ENERGI LISTRIK DENGAN PEMANFAATAN ANDROID DAN BLUETOOTH
}

\section{${ }^{1}$ Isnawaty, ${ }^{1}$ Sri Astuti Mayangsari, ${ }^{2}$ Aditya Rachman}

\author{
${ }^{1}$ Jurusan Teknik Informatika, Universitas Halu Oleo Kendari \\ ${ }^{2}$ Program Studi Teknik Mesin Fakultas Teknik Universitas Halu Oleo, Kendari \\ e-mail: isnawaty@uho.ac.id, sriastuti.mayangsariel@gmail.com, aditya_rchmn@yahoo.com
}

\begin{abstract}
Abstrak
Efisiensi penggunaan listrik merupakan salah satu aktivitas penting saat ini, karena keterbatasan dan dampak negatif terhadap lingkungan dari sumber-sumber energi fosil yang digunakan saat ini. Salah satu komponen yang mengkonsumsi energi listrik adalah penggunaan penerangan ruangan. Pengaturan pengoperasian penerangan kebanyakan dilakukan secara manual, dimana kurang efektif dan efisien. Hal ini disebabkan sistem kendali manual bergantung kepada seorang atau beberapa operator untuk menghidupkan atau mematikannya. Penelitian ini bertujuan merancang dan mengimplementasikan sistem kendali penerangan ruangan, yaitu menyalakan dan memadamkan serta mendeteksi penghuni dalam ruangan melalui smartphone android dan Mikrokontroler dengan memanfaatkan koneksi bluetooth. Teknologi keduanya dapat menciptakan sebuah alat dengan sistem yang dapat mempermudah dalam hal pengendalian listrik. Handphone android akan digunakan sebagai sentral pengendali (Tx) dengan penekanan tombol instruksi pada aplikasi yang dibangun pada android sebagai interface ke sistem mikrokontroler. Aplikasi dibangun dengan menggunakan metode pengembangan prototype sehingga dapat mengefisienkan waktu pengerjaan. Berdasarkan hasil pengujian yang dilakukan, sistem dapat bekerja dengan baik sesuai dengan tujuan. Program sistem kendali yang dibuat dapat dijalankan pada sistem operasi android, yang dapat difungsikan menyalakan dan memadamkan lampu sebanyak 3 buah. Pada pengujian yang dilakukan dengan menggunakan halangan dan tanpa halangan didapatkan jarak maksimal untuk pengontrolan dengan menggunakan halangan dapat berjalan dengan baik pada jarak $\pm 9 \mathrm{~m}$, dan untuk pengujian tanpa halangan pengontrolan dapat berjalan baik hingga jarak $\pm 25 \mathrm{~m}$.
\end{abstract}

Kata Kunci : Sistem kendali, penerangan ruangan, energi, bluetooth, android

\begin{abstract}
The control system for the room lighting to reduce the energy consumption by implementing Android and Bluetooth. The Efficiency on the use of electricity is one of the important activities at this time, due to the limitations and negative environmental impacts of fossil energy sources used today. One of the components that consume the electrical energy is the use of lighting for a room. In present day, to control the operation of the lighting mostly is conducted manually, which is less effective and efficient, consuming more energy. This is due to manual control systems relies on only operators to turn on or turn it off. This research aims to design and implement a system to control lights as lighting equipment room, which turns on/off, and detects the occupants in the room through the Android Smartphone and Microcontroller by using a Bluetooth connection. Both technologies could create a tool with a system that could facilitate the control of electricity. Android phone will be used as a central controller (Tx) by pressing a key instruction on application built on Android as an interface to the system microcontroller. Applications built using prototype development to minimize the processing time. Based on the results of tests performed, the system can work well in accordance with the purpose. Program control system created to run on the Android operating system can turn on and off lights as much as 3 pieces. On the tests carried out using a hitch and without hindrance, the maximum distances for control by using obstacle could run well at a distance of $\pm 9 \mathrm{~m}$, and for testing without a hitch control can either walk up to a distance of $\pm 25 \mathrm{~m}$.
\end{abstract}

Keywords: Lighting control, room, energy, bluetooth, android 


\section{Pendahuluan}

Perkembangan teknologi dan gaya hidup saat ini menunjukkan semakin pentingnya kepraktisan yang menyebabkan kebutuhan untuk mengontrol berbagai alat listrik tidak hanya dilakukan dengan mengharuskan seseorang berada di dekat piranti listrik. Dengan perkembangan teknologi saat ini, maka kebutuhan peralatan listrik atau elektronik di rumah, seperti menyalakan lampu rumah, menyalakan televisi atau radio, serta menyalakan berbagai peralatan rumah tangga, kegiatan itu semua lebih praktis jika bisa dikontrol dan dikendalikan dengan baik melalui aplikasi pengendali peralatan listrik.

Salah satu masalah yang yang membutuhkan kepraktisan dalam aplikasinya adalah pengaturan penerangan dalam ruangan. Keterbatasan waktu, tenaga dan memori manusia untuk selalu mengatur penerangan adalah kendala pada sistem manual. Penerangan merupakan isu penting saat ini karena konsumsi energi yang besar (Rachman, 2014). Pengontrolan penerangan yang baik dapat mengurangi konsumsi energi listrik.

Penelitian ini bertujuan merancang dan mengimplementasikan sistem untuk mengontrol lampu sebagai alat penerangan ruangan, yaitu menyalakan dan memadamkan serta mendeteksi penghuni dalam ruangan melalui smartphone android dan mikrokontroler dengan memanfaatkan koneksi bluetooth.

\section{Landasan Teori}

\section{Sistem Kendali}

Sistem kendali merupakan bagian yang terintegrasi dari sistem kehidupan modern saat ini, seperti kendali suhu ruang, mesin cuci, robot, pesawat, dan lain sebagainya. Dengan sistem kendali memungkinkan adanya sistem yang stabil, akurat, dan tepat waktu. Sistem kendali dapat dirancang melakukan pengendalian secara otomatik (Kuphaldt, 2010).

Secara umum ada empat aspek yang berkaitan dengan sistem pengendalian yaitu masukan, keluaran, sistem dan proses. Masukan (input) adalah rangsangan dari luar yang diterapkan ke sebuah sistem kendali untuk memperoleh tanggapan tertentu dari sistem pengaturan. Keluaran (output) adalah tanggapan sebenarnya yang didapatkan dari suatu sistem kendali. Sistem kendali dapat dikatakan sebagai hubungan antara komponen yang membentuk sebuah konfigurasi sistem, yang akan menghasilkan tanggapan sistem yang diharapkan. Jadi harus ada yang dikendalikan, yang merupakan suatu sistem fisis, yang biasa disebut dengan kendalian (Brady, 2011 dan Distefano, dkk, 1984).

\section{Android}

Android adalah sistem operasi untuk telepon seluler berbasis Linux sebagai kernelnya. Android begitu pesat perkembangan di era saat ini karena Android menyediakan platform terbuka (open source) bagi para pengembang untuk menciptakan aplikasi mereka sendiri (Farhad, 2015, Nazaruddin, 2011).

Beberapa bagian penting dalam pengembangan android adalah android SDK dan android Bluetooth API. Android SDK (Software Development Kit) adalah tools API (Application Programming Interface) yang disediakan Google sebagai sarana untuk mengembangkan aplikasi pada platform Android dengan menggunakan bahasa Java. Android SDK meliputi proyek sampel dengan kode sumber, perangkat pengembangan, sebuah emulator, dan perpustakaan yang diperlukan untuk membangun aplikasi Android (Syed, 2013).

Android Bluetooth API merupakan platform Android berisi dukungan untuk jaringan Bluetooth, yang memungkinkan perangkat berbasis Android untuk bertukar data secara nirkabel dengan perangkat Bluetooth lainnya. Kerangka aplikasi menyediakan akses ke fungsionalitas Bluetooth melalui Android Bluetooth API. API ini memungkinkan aplikasi secara nirkabel terhubung ke perangkat Bluetooth lainnya, fitur memungkinkan point to- point dan multipoint nirkabel. Android Bluetooth API tersedia dalam Android. (Syed, 2013).

Dengan menggunakan Android BluetoothAPI, sebuah aplikasi Android dapat menscan perangkat bluetooth lain, menetapkan RFCOMM saluran, menghubungkan perangkat lain melalui penemuan layanan, mentransfer data ke dan dari perangkat lain dan mengelola koneksi multiple (Newton, 2007)

\section{Mikrokontroler}

Mikrokontroler adalah suatu mikroprosessor yang dikombinasikan dengan periperal I/O dan 
memori (RAM/ROM) dalam bentuk single chip. Semua tipe memiliki CPU yang sama, RAM, counter/timer, port paralel dan serial. Mikrokontroler merupakan komputer didalam chip yang digunakan untuk mengontrol peralatan elektronik, yang menekankan efisiensi dan efektifitas biaya. Secara harfiahnya bisa disebut little control dimana sebuah sistem elektronik yang sebelumnya banyak memerlukan komponen-komponen pendukung seperti IC TTL dan CMOS dapat direduksi/ diperkecil (Stan, 1983). ATMega328 adalah mikrokontroller keluaran dari atmel yang mempunyai arsitektur RISC (Reduce Instruction Set Computer) yang dimana setiap proses eksekusi data lebih cepat dari pada arsitektur CISC (Completed Instruction Set Computer) (Amtel Corp, 2016).

\section{Bluetooth}

Bluetooth adalah salah satu bentuk komunikasi data secara nirkabel berbasis frekuensi radio. Penggunaan utama dari modul bluetooth ini adalah menggantikan komunikasi serial menggunakan kabel. Bluetooth terdiri dari dua jenis perangkat, yaitu Master (pengirim data) dan Slave (penerima). Agar dapat berkomunikasi dua sistem mikrokontroler ini maka dipasang sebuah modul Bluetooth Master pada satu sistem dan modul Bluetooth Slave pada sistem lainnya. Komunikasi dapat langsung dilakukan setelah kedua modul bluetooth melakukan pairing koneksi. Koneksi melalui bluetooth ini menyerupai komunikasi serial komunikasi biasa, yaitu adanya pin komunikasi TXD dan pin komunikasi RXD (Daryanto, 2011).

Kelebihan sistem bluetooth adalah dapat menembus berbagai rintangan seperti dinding, kotak, dan sebagainya walaupun jarak maksimalnya hanya $10 \mathrm{M}$, tidak memerlukan kabel atau kawat, dapat me-singkronisasi data dari HP ke Komputer dan dapat digunakan sebagai perantara modem. Adapun kekurangan system bluetooth adalah jika terlalu banyak koneksi bluetooth dalam satu ruangan sulit untuk menemukan penerima yang diharapkan. Selain itu, banyak mekanisme keamanan yang harus diperhatikan untuk mencegah kegagalan pengiriman atau penerimaan informasi (Daryanto, 2011).

Bluetooth HC-06 merupakan seri B dari beberapa seri bluetooth untuk mikrokontroler. Kemampuan dalam memancarkan pancaran sinyal/gelombang bluetooth termasuk dalam kategori excellent. Bluetooth HC-06 berfungsi sebagai Slave (penerima) dengan kekuatan pemancar yang sangat baik. Oleh karenanya Bluetooth HC-06 dapat berfungsi dengan baik hingga jarak lebih dari 10m (Heriyanto, 2011)

Sistem mikrokontroler yang terpasang modul Bluetooth Slave dapat berkomunikasi dengan perangkat lain seperti laptop, ponsel, smartphone, GPS dan lain-lain yang dilengkapi adapter bluetooth. Agar dua buah perangkat dapat saling terkoneksi maka Disamping itu kedua perangkat harus saling mencocokkan password saat proses pairing (saat menghubungkan perangkat bluetooth) (Widodo, 2008).

\section{Passive Infrared Receiver (PIR)}

Passive Infrared Receiver (PIR) merupakan sebuah sensor berbasiskan infrared. Passive Infrared Receiver (PIR) tidak memancarkan apapun seperti infra red. Sesuai dengan namanya 'Passive', sensor ini hanya merespon energi dari pancaran sinar inframerah pasif yang dimiliki oleh setiap benda yang terdeteksi olehnya. Benda yang bisa dideteksi oleh sensor ini biasanya adalah tubuh manusia. Sensor Passive Infrared Receiver (PIR) ini bekerja dengan menangkap energi panas yang dihasilkan dari pancaran sinar inframerah pasif yang dimiliki setiap benda dengan suhu benda di atas nol mutlak. Seperti tubuh manusia yang memiliki suhu tubuh kirakira 32 derajat celcius, yang merupakan suhu panas yang khas yang terdapat pada lingkungan (Hallee, 2016).

\section{IDE Arduino}

Arduino adalah suatu minimum sistem yang menggunakan IC dari keluarga AVR dan bersifat open source dengan nama produk Arduino. Arduino menggunakan bahasa pemrograman sendiri yang menyerupai bahasa C. Untuk melakukan pemrograman pada Arduino, digunakan software yang dirancang khusus untuk memprogram Arduino, yaitu Arduino IDE. Arduino IDE dibuat dari bahasa pemrograman Java. Arduino IDE juga dilengkapi dengan library $\mathrm{C} / \mathrm{C}++$ yang biasa disebut wiring yang membuat operasi input dan outputnya menjadi lebih mudah (Arduino, 2016). 


\section{DINAMIKA Jurnal IImiah Teknik Mesin}

\section{Metodologi}

\section{Gambaran Umum Sistem}

Secara umum sistem dibuat agar dapat menerima perintah kendali terhadap peralatan listrik dari Smartphone Android. proses kerja sistem kendali secara umum yaitu pengguna mengaktifkan bluetooth pada Smartphone Android dan menghubungkannya dengan modul bluetooth yang telah terpasang pada sismin mikrokrontroler. Jika proses koneksi antar bluetooth telah berhasil, kemudian pengguna dapat membuka aplikasi Sistem Pengendali penerangan ruangan pada Smartphone Android dan melakukan proses kendali pada lampu, yaitu menyalakan dan memadamkan lampu (on/off).

Ketika pengguna melakukan input berupa on/off pada sistem, maka perintah tersebut akan dikirimkan melalui koneksi bluetooth yang sudah terlebih dahulu saling terkoneksi. Selanjutnya perintah tersebut akan diproses oleh mikrokontroler. Mikrokontroler akan melanjutkan perintah tersebut ke relay, dan mikrokontroler akan memilih relay mana yang akan menjalankan perintah on/off dari pengguna.

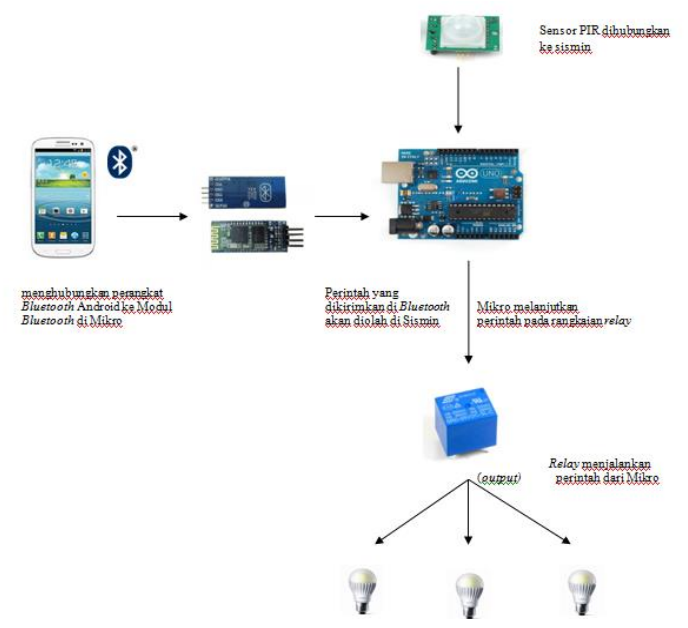

Gambar 1 Arsitektur Sistem Pengendali Listrik

Sensor PIR berfungsi untuk mendeteksi keberadaan orang dalam ruangan. Sensor PIR dihubungkan pada sistim minimum mikrokontroler dan akan memberikan pesan pada user, jika sensor mendeteksi adanya orang, maka akan ada pemberitahuan pada user. Arduino akan mengirimkan pesan untuk user bahwa ruangan tersebut terdapat penghuni didalamnya dan begitupun sebaliknya, jika tidak terdapat manusia dalam ruangan maka Arduino akan mengirimkan pesan bahwa ruangan kosong pada user sehingga dapat memberikan pertimbangan pada user untuk melakukan kendali on/off.

\section{Flowchart}

Untuk lebih memahami alur kerja sistem, berikut ditampilkan diagram alir yang menunjukkan bagaimana sistem bekerja mulai dari awal hingga sistem berakhir.

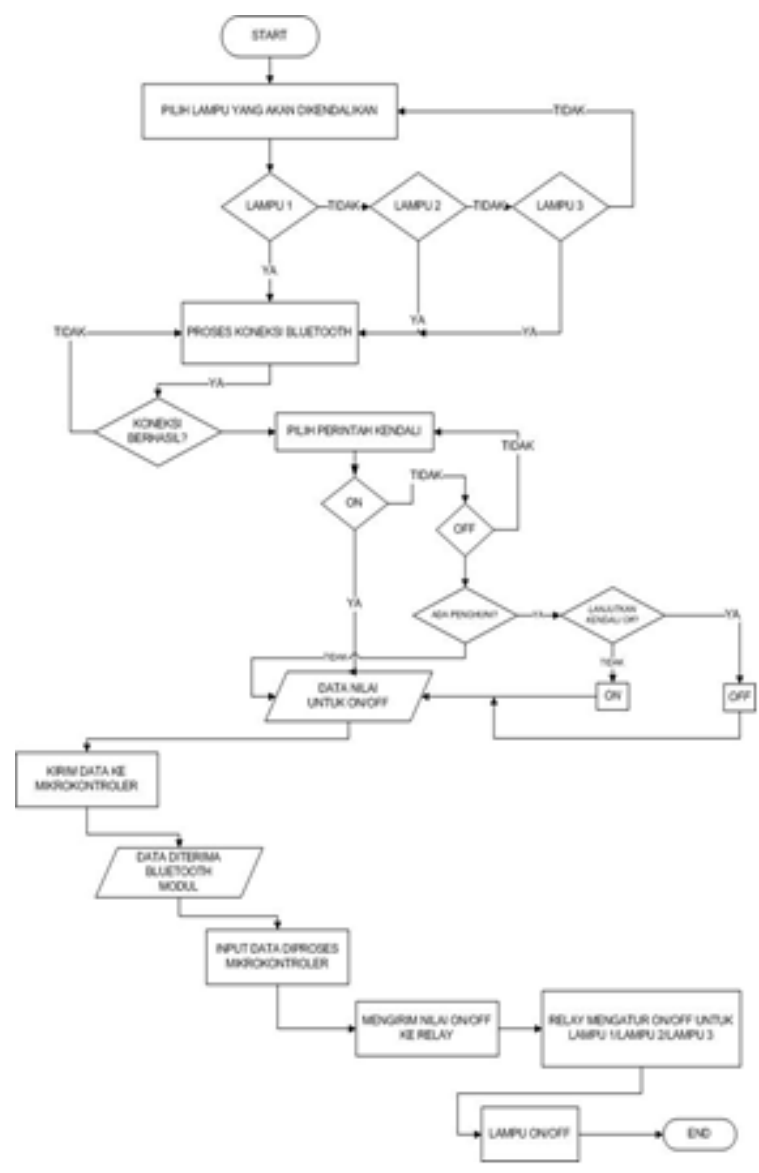

Gambar 2 Flowchart Program

Sistem dimulai dengan pengguna memilih perangkat lampu yang akan dikendalikan. Terdapat 3 buah lampu yang dapat dikendalikan pada prototype ini. Setelah itu, jika bluetooth pada masing-masing perangkat telah saling terkoneksi maka selanjutnya pengguna dapat melakukan proses kendali berupa menyalakan atau memadamkan lampu (on/off). Selanjutnya perintah yang dimasukkan akan mengirim data ke mikrokontroler melalui modul bluetooth. Jika 
user melakukan kendali off maka akan Arduino akan memberi pesan berupa kondisi ruangan, apakah ruangan itu kosong atau ruangan tersebut berpenghuni.

Mikrokontroler akan mendeteksi adanya penghuni dalam ruangan dengan membaca suhu tubuh manusia dan dikirimkan ke mikrokontroler sehingga user mendapatkan informasi jika ruangan tersebut terdapat orang atau tidak. Mikrokontroler kemudian memproses perintah dan mengirim perintah on/off ke relay. Relay berfungsi sebagai pengganti saklar yang bertugas untuk menyambung dan memutuskan arus. Setelah perintah sampai ke relay, kemudian relay menentukkan lampu berapa yang akan dikendalikan sesuai dengan input yang dilakukan oleh pengguna. Setelah lampu menyala/padam, maka proses berakhir.

\section{Hasil}

\section{Implementasi Program Sistem Kendali}

Program Sistem Kendali dirancang dengan menggunakan bahasa pemograman java, dan juga bahasa pemograman C. Program Sistem Kendali yang dimasukkan kedalam mikrokontroler diterjemahkan menggunakan bahasa $\mathrm{C}$ dengan menggunakan software IDE Arduino. Inti dari program sistem kendali yang dirancang adalah pengguna dapat menyalakan serta memadamkan lampu dengan memanfaatkan fasilitas bluetooth yang ada pada perangkat Android.

\section{Interface pada Smartphone Android}

Interface bertujuan untuk memudahkan pengguna dalam menggunakan sistem kendali yang dirancang. Interface didesain dengan tampilan yang menarik dan sederhana agar pengguna dapat dengan mudah menggunakannya. Tampilan interface pada Smartphone Android terbagi menjadi form untuk tampilan utama menu serta form untuk tampilan dalam menu. Berikut adalah tampilan yang telah didesain untuk Rancang Bangun Pengendali Perangkat Listrik Berbasis Mikrokontroler ATMega328 pada Smartphone Android.

\section{Tampilan}

Menu utama terdiri dari tiga buah tombol, masing-masing berfungsi untuk pengendalian pada lampu 1, lampu 2, dan lampu 3.

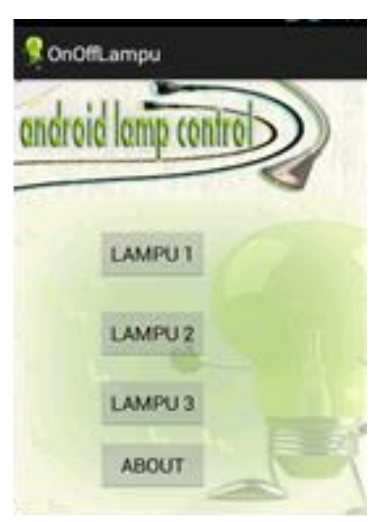

Gambar 3 Tampilan Main Menu

Tampilan menu untuk lampu 1, lampu 2, dan lampu 3 disesuaikan dengan tujuan dari sistem kendali, yaitu untuk menyalakan serta memadamkan lampu. Jadi, dalam menu hanya terdapat dua buah tombol, yaitu tombol untuk menyalakan dan tombol untuk memadamkan lampu. Berikut adalah tampilan dari form Menu.

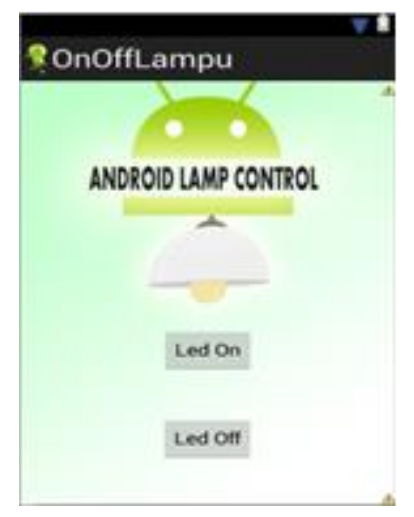

Gambar 4 Tampilan Menu

\section{Pengujian Lampu dengan Halangan}

Pengujian dilakukan pada lampu dengan halangan. Halangan diwakili oleh media dinding atau tembok. Jarak maksimal dengan adanya penghalang adalah kurang lebih $9 \mathrm{~m}$ (tabel 1). Ketika mendekati 9 m respon untuk menyalakan serta memadamkan lampu mulai lambat. Ketika diuji pada jarak $>9 \mathrm{~m}$, tidak terjadi respon alat terhadap perintah on/off. 


\section{DINAMIKA Jurnal IImiah Teknik Mesin}

Tabel 1 Tabel Pengujian Lampu Dengan Halangan

\begin{tabular}{|l|c|c|c|c|c|}
\hline Perintah & Waktu & $\begin{array}{c}\text { Jarak } \\
\text { HP - } \\
\text { dinding }\end{array}$ & $\begin{array}{c}\text { Jarak } \\
\text { Mikro - } \\
\text { dinding }\end{array}$ & Status LED & Kesimpulan \\
\hline ON & $1 \mathrm{~s}$ & $1 \mathrm{~m}$ & $4 \mathrm{~m}$ & Menyala & Sukses \\
\hline OFF & $1 \mathrm{~s}$ & $1 \mathrm{~m}$ & $4 \mathrm{~m}$ & Padam & Sukses \\
\hline ON & $1 \mathrm{~s}$ & $3 \mathrm{~m}$ & $4 \mathrm{~m}$ & Menyala & Sukses \\
\hline OFF & $1 \mathrm{~s}$ & $3 \mathrm{~m}$ & $4 \mathrm{~m}$ & Padam & Sukses \\
\hline ON & $1 \mathrm{~s}$ & $6 \mathrm{~m}$ & $3 \mathrm{~m}$ & Menyala & Sukses \\
\hline OFF & $1 \mathrm{~s}$ & $6 \mathrm{~m}$ & $3 \mathrm{~m}$ & Padam & Sukses \\
\hline ON & $2 \mathrm{~s}$ & $7 \mathrm{~m}$ & $5 \mathrm{~m}$ & Padam & Gagal \\
\hline ON & & & $>9 \mathrm{~m}$ & $\begin{array}{c}\text { Tidak } \\
\text { Menyala }\end{array}$ & Gagal \\
\hline
\end{tabular}

Tabel 2 Tabel Pengujian Lampu Tanpa Halangan

\begin{tabular}{|c|c|c|c|c|}
\hline Perintah & Waktu (s) & Jarak (m) & Status LED & Kesimpulan \\
\hline $\mathbf{O N}$ & $1 \mathrm{~s}$ & $1 \mathrm{~m}$ & Menyala & Sukses \\
\hline OFF & $1 \mathrm{~s}$ & $1 \mathrm{~m}$ & Padam & Sukses \\
\hline ON & $1 \mathrm{~s}$ & $2 \mathrm{~m}$ & Menyala & Sukses \\
\hline OFF & $1 \mathrm{~s}$ & $2 \mathrm{~m}$ & Padam & Sukses \\
\hline $\mathbf{O N}$ & $1 \mathrm{~s}$ & $5 \mathrm{~m}$ & Menyala & Sukses \\
\hline OFF & $1 \mathrm{~s}$ & $5 \mathrm{~m}$ & Padam & Sukses \\
\hline ON & $1 \mathrm{~s}$ & $10 \mathrm{~m}$ & Menyala & Sukses \\
\hline OFF & $1 \mathrm{~s}$ & $10 \mathrm{~m}$ & Padam & Sukses \\
\hline ON & $1 \mathrm{~s}$ & $15 \mathrm{~m}$ & Menyala & Sukses \\
\hline OFF & $1 \mathrm{~s}$ & $15 \mathrm{~m}$ & Padam & Sukses \\
\hline $\mathbf{O N}$ & $1 \mathrm{~s}$ & $20 \mathrm{~m}$ & Menyala & Sukses \\
\hline OFF & $1 \mathrm{~s}$ & $20 \mathrm{~m}$ & Padam & Sukses \\
\hline ON & $2 \mathrm{~s}$ & $25 \mathrm{~m}$ & Menyala & Sukses \\
\hline OFF & $2 \mathrm{~s}$ & $25 \mathrm{~m}$ & Padam & Sukses \\
\hline ON & & $>25 \mathrm{~m}$ & Tidak Menyala & Gagal \\
\hline
\end{tabular}




\section{Pengujian Lampu tanpa Halangan}

Hasil pengujian sistem kendali tanpa halangan berdasarkan pada jarak pengendalian dapat dilihat di tabel 2. Berdasarkan pengujian yang dilakukan pada lampu 1, lampu 2, dan lampu 3 didapatkan hasil maksimum untuk jarak pengendalian adalah kurang lebih $25 \mathrm{~m}$. Jarak ini $15 \mathrm{~m}$ lebih jauh dari jarak rata-rata yang dapat dikendalikan dengan bluetooth. Perangkat Bluetooth HC-06 memiliki jarak pancaran sinyal yang sangat baik untuk seri Bluetooth pada Mikrokontroler. Bluetooth HC-06 memiliki spesifikasi Jika rata-rata Bluetooth hanya mampu mengendalikan maksimal $10 \mathrm{~m}$, maka pada penelitian pengendalian dengan menggunakan Bluetooth HC-06, peneliti mendapatkan hasil kurang lebih $25 \mathrm{~m}$. Namun, pada jarak mendekati $25 \mathrm{~m}$ respon yang diberikan menjadi lebih lambat.

\section{Kesimpulan dan Saran}

Penelitian ini telah mendesain dan menguji kemampuan smartphone android untuk mengendalikan penerangan ruangan menggunakan fasilitas Bluetooth sebagai media komunikasi. Sistem pengendali penerangan dapat dioperasikan dengan baik. Dari hasil pengujian dapat disimpulkan bahwa pengontrolan dengan sistem ini dapat bekerja baik pada jarak maksimal kurang lebih 25 meter (pada ruangan tanpa penghalang) dan kurang lebih 9 meter ( untuk ruangan dengan halangan). Hasil pengujian juga menunjukkan tidak terdapat selisih waktu pengontrolan antara waktu eksekusi yang diinginkan dengan waktu pelaksanaan eksekusi hardware.

Agar pada pengembangan selanjutnya diharapkan pengontrolan sistem tidak lagi dibatasi oleh jarak sehingga pengontrolan dapat dilakukan dari jarak jauh. Hal ini dapat dilakukan dengan mengganti komunikasi data menjadi secara online, atau melalui pesan pendek (SMS). Selain itu, dapat dilakukan penambahan fitur sistem kendali, berupa fitur penjadwalan lampu secara otomatis atau fitur dimmer untuk mengatur intensitas cahaya lampu.

\section{Daftar Pustaka}

Amtel Corp, 2016, MicroChipATmega328
Arduino, 2016, "Arduino - Introduction". arduino.cc.

Brady, I, 2011, "Programmable logic controllers benefits and applications" (PDF). PLCs.

Daryanto. 2011. Pengetahuan Teknik Elektronika. Jakarta: Bumi Aksara.

Distefano J.J.dkk, 1984. Sistem Pemgendalian dan Umpan Balik Seri buku Schaum. Jakarta : Erlangga.

Farhad M, 2015. "A Murky Road Ahead for Android, Despite Market Dominance". The New York Times. ISSN 0362-4331.

Hallee D. "Passive Infrared Sensors: A Brief Overview". InHomeSafetyGuide.org. In Home Safety Guide. Retrieved 6 May 2016.

Heriyanto B. 2011. "Esensi - esensi Bahasa Pemrograman Java". Bandung : Informatika.

Kuphaldt, TR. 2010, "Chapter 6 LADDER LOGIC". Lessons In Electric Circuits -Volume IV.

Nazruddin.S, 2011. Android, Pemrograman Aplikasi Mobile Smartphone dan Tablet PC Berbasis Android. Bandung : Informatika.

Newton, H, 2007. Newton's telecom dictionary. New York: Flatiron Publishing.

Rachman A, Aspin, Belinda S, 2014 The effect of circulating fan and natural ventilation on the thermal comfort performance in a building in Southeast Sulawesi, Jurnal Ilmiah Teknik Mesin Vol 5, No 2

Syed H, 2014, "Editorial: Why You Should Go Nexus". Droid Lessons. Retrieved April 17, 2013.

Stan A, 1983. The Most Widely Used Computer on a Chip: The TMS 1000. State of the Art: A Photographic History of the Integrated Circuit (New Haven and New York: Ticknor \& Fields). ISBN 0-89919195-9.

Widodo H. 2008. Mari Kita Kenali Komponen Elektronika. Banten: Panca Anugerah Sakti. 
DINAMIKA Jurnal Ilmiah Teknik Mesin 